\title{
Importance of Dried Fruits and Vegetables in the Older Adults
}

\author{
(D) Tahir Belice1, (1) Arif Yüksel1, (1) Selahattin Fehmi Akçiçek² \\ 1 University of Health Sciences Turkey, Izmir Bozyaka Training and Research Hospital, Clinic of Internal Diseases, Izmir, Turkey \\ 2Ege University Faculty of Medicine, Department of Internal Medicine, Division of Gertiatrics, Izmir, Turkey
}

\begin{abstract}
Several studies have shown that dietary factors play a role in the development and course of chronic diseases. In modern societies, we now observe a transition from a diet mainly comprising fruits and vegetables that are rich in fibres, micronutrients and antioxidants by way of which we have survived due to the adaptation mechanisms we have developed for centuries to a diet that is high in calories but poor in fibres and vitamins. Finding rational solutions to the problem of expanding elderly population would only be possible with a holistic and proactive approach. In this review, we aimed to investigate the positive effect of the long-term use of dried fruits and vegetables, which are as old as the history of mankind, on various pathologic processes that occur as a result of ageing in conjunction with the available studies.
\end{abstract}

Keywords: Aged, vegetables, fruit, diet, vitamins, micronutrient

\section{Introduction}

Communities all over the world are now analysing the problems of the expanding elderly population to find solutions, while the importance of preventive healthcare services comes up repeatedly. It has become more difficult to finance the healthcare system due to reasons such as the need for conducting followup and providing treatment for diseases after they occur and the loss of active workforce. Malnutrition is a common Geriatric syndrome in the elderly and it is caused by eating an insufficient and imbalanced diet; it might have various other aetiologies as well. The prevalence of malnutrition may be up to 50\% among the elderly (1). Health problems become inevitable because older people become more vulnerable to malnutrition and we cannot develop accurate and effective eating strategies or be aware and predict the problems that might occur. During this critical period of human life, geriatric syndromes such as sarcopenia, falls and frailty increase in prevalence in the presence of decreasing physiological and functional reserves $(2,3)$. Moreover, malnutrition leads to a decline in mental and physical functions, there by rendering older adults unable to pursue their lives independently, causing an increased need for nursing homes and caregivers (4). The majority of older people who need care survive with the assistance of their relatives in many countries. Efforts to be taken by patients' relatives and healthcare professionals would make it possible to identify older adults who are at risk of malnutrition and to provide rational advice. This review aims to underline the importance of dried fruits and vegetables in dietary models that would contribute to the health of the elderly and reduce the increasing socioeconomic burden of the elderly population.

\section{History of Dried Fruits and Vegetables}

Food begins to decay right after it is harvested. Therefore, our ancestors had to find a way to store and use food in the long term to survive $(5,6)$. The storage and preservation of food dates back to 12.000 B.C. and sun-drying is one of the most frequently used methods during the prehistoric times (7). In late 1700s, Napoleon offered 12.000 French francs to anyone who could find a method to preserve food during transportation to feed his army during war (8). The Ottoman Sultan Selim I crossed

Address for Correspondence: Tahir Belice, University of Health Sciences Turkey, İzmir Bozyaka Training and Research Hospital, Clinic of Internal Diseases, İzmir, Turkey

Phone: +90 5062817530 E-mail: tahirbelice@gmail.com ORCID: orcid.org/0000-0001-7957-3423

Received: Feb 06, 2020 Accepted: Mar 23, 2020

Cite this article as: Belice T, Yüksel A, Akçiçek SF. Importance of Dried Fruits and Vegetables in the Older Adults. Eur J Geriatr Gerontol 2020;2(2):28-35

๑Copyright 2020 by the Academic Geriatrics Society / European Journal of Geriatrics and Gerontology published by Galenos Publishing House. 
the Sinai desert during a military campaign to Ridaniye and it is known that there was Kahramanmaraş tarhana, which is made by mixing and drying yoghurt, wheat and spices, in the supply convoy of his army (9). Moreover, the French inventors Masson and Chollet used vegetables that were dried by heating to 105 degrees Fahrenheit and used as long-lasting and light-weight food for the soldiers during World War II (10). Dried vegetables and fruits are still important and commonly used in daily life in the third world countries. Indeed, developed countries are faced with increasing incidence of malnutrition because people tend to eat cheap food that is low in nutritional value due to the high cost of living (11).

\section{Drying and Storage Methods}

Drying is one of the oldest food preservation methods. Fruits, meat, grains and vegetables have been dehydrated for longterm storage by methods such as sun-drying, wind-drying and smoking throughout history (12). These methods are fundamentally based on the removal of water by hot air passing through the food, which inhibits the activity of enzymes and bacteria in food. Our ancestors learnt to store meat by freezing in regions with very a cold climate and to store food by sun-drying in regions with hot, tropical climates. Eventually, they managed to establish a civilisation by settling in a region and abandoning nomadic life because they started to preserve and store food during the early times of humankind. The history of dried fruits and vegetables dates back to 12.000 B.C. and evidence shows that dried foods were actively used in the Middle East and in the oriental culture (13). In 1900s, people started to dry food using dehydrators in regions where the sun and wind were insufficient (13). The purpose of drying fruits and vegetables is to prolong storage, reduce the need for packaging and decrease the weight during transportation. Fibres, minerals and vitamins are among the important essential elements found in fruits and vegetables. They spoil easily when humidity is $>80 \%$.

Drying is the best way to maintain nutritional value at the optimal level. Throughout the world, nearly $20 \%$ of the produce is dried after harvest to prolong the shelf life and to enhance the long-term safety of the produce (14). Dried fruits and vegetables or foods that have a low level of water activity were previously thought to be microbiologically safe. However, it was later observed that such foods caused outbreaks of food poisoning because they provided a suitable environment for some pathogens. Dried foods are safe against microbial damage. It is difficult for microorganisms to reproduce below a critical water activity score, but this does not mean that the products are sterile (15). Existing bacteria can reproduce during rehydration. On the other hand, the microflora changes depending on the properties of the food, $\mathrm{pH}$, composition, drying method, contaminating organism and pre-treatment. Moreover, the addition of salt remarkably reduces the microbial load (16). Later, with advancements in technology, new methods such as irradiation, high-pressure processing and pulsed electric field were found that enabled us to consume dried fruits and vegetables with the least harm and maximum benefit (14).

\section{Benefits of Dried Fruits and Vegetables in the Elderly}

\section{Increased Need for Micronutrients}

Ageing occurs with decreased appetite and disrupted tendency to eat due to decreased basal metabolic rate, which in turn leads to an increased need for micronutrients (17). Chronic diseases that increase with ageing result in increased need for micronutrients. Furthermore, the presence of concomitant Malabsorption syndromes disrupts micronutrient absorption as well as the utilisation processes. In addition, increased use of some medications that are frequently used in the elderly such as acid suppressants may lead to micronutrient deficiencies (1820). Moreover, increased incidence of conditions that negatively affect the intestinal microflora such as the use of certain medications and frequent hospitalisation, recurring infections, changes in the intestinal morphology and physiology, decreased intestinal functions, weakened immune system, lower mobility and changing lifestyle and eating habits due to ageing also increase micronutrient deficiencies (21-25). Because of poor hygiene, parasitic diseases are more common in the elderly, leading to nutritional deficiencies $(26,27)$.

A study that investigated dietary microelements intakes status in the elderly people from different areas in Zhejiang Province in 2010-2012 reported an increase in the need for microelements that further reached significant levels, especially in certain regions (28). Insufficient micronutrient intake in the elderly causes health problems, possibly leading to loss of labour and increased healthcare expenses. The increased need for micronutrients in the elderly can be met to some extent by the regular intake of dried fruits and vegetables (29). Dried fruits and vegetables are not rich in salt and vitamin B12; however, they are rich in vitamin $C$, vitamin $D$, vitamin $\mathrm{E}$, thiamine, niacin, riboflavin and folate. In addition, they also contain high amounts of calcium, phosphorus, magnesium, iron, zinc and potassium. Dried tomatoes can preserve their vitamin $\mathrm{C}$ content at the highest possible level and can meet most of the daily vitamin $\mathrm{C}$ requirement (30-32). Another study showed that the consumption of frozen fruits and vegetables led to higher potassium, calcium, fibre and vitamin $\mathrm{D}$ intakes and lower sodium intake, wherein those who consumed frozen fruits and vegetables also had increased consumption of other forms of food such as fresh, canned or dried food (33). Furthermore, such high consumption of fruits and vegetables led to considerable reductions in the body mass indices of these individuals (33). 


\section{Decreased Consumption of Fibre}

In addition to the above mentioned features, dried fruits and vegetables contain a high amount of fibre, which makes them more important for health $(34,35)$. Like in other age groups, the dietary intake of fibre remains below the desired level in a majority of older adults (36). The Institute of Medicine recommends a daily intake of dietary fibre of up to $38 \mathrm{mg}$ depending on age and gender (37). Increased fibre intake may lead to low blood pressure, low lipid levels and decreased fasting blood glucose and $\mathrm{HbA1C}$ levels and increased insulin sensitivity, there by resulting in a low incidence of diseases such as Diabetes Mellitus, hyperlipidaemia and cardiovascular diseases that have increased global health burden and cause considerable mortality and morbidity $(38,39)$. According to the nurses' health study, there was a significant relationship between increased dietary fibre intake and decreased incidence of faecal incontinence among 60.000 older women (40). Another prospective cohort study that lasted for 13.1 years and included 1982 patient groups showed a statistically significant negative correlation between high dietary fibre intake and chronic obstructive pulmonary disease in ex-smokers and current smokers (41). Moreover, increased fibre intake was found to be associated with decreased incidence of ovarian cancer, premenopausal breast cancer, oesophageal cancer and colorectal cancer (4245). Adding dried fruits and vegetables to the diet plan would make it easier to reach the target level of fibre intake in the elderly.

\section{Increased Burden of Oxidants in the Elderly}

Decreased intake of foods that contain antioxidants such as vitamin $C$, vitamin $E$ and selenium and increased incidence of chronic diseases in the elderly lead to a high burden of oxidants in the body, which in turn may result in the development of new pathological conditions or negatively affect the course of existing diseases $(46,47)$. The inadequacy of antioxidant mechanisms against the increased oxidant burden in the elderly points out the importance of foods that contain antioxidant components (48).

The oxidant burden that increases with age plays a role in the aetiology of various chronic diseases such as cancer, cardiovascular diseases, cataract, age-related macular degeneration and ageing; the oxidation of proteins and nucleic acids is believed to have a potential role in this increase (49). In western populations, the majority of deaths are caused by atherosclerosis, whereas potent antioxidants such as beta carotene, vitamin $\mathrm{E}$, vitamin $\mathrm{C}$, polyphenol and lycopene are considered to prevent atherogenesis (50-52). Thus, ageing populations can be recommended to consume dried fruits and vegetables because they contain a considerable amount of antioxidants. Thereby, it is possible to enhance the quality of life, decrease the incidence of diseases and reduce disease severity in the elderly.

\section{Oral and Dental Health Problems}

Concerning nutrient intake, decrease in the amount and diversity of consumed food has a negative effect on the oral and dental health $(52,53)$. The deterioration of oral and dental health in the elderly constitutes a risk for malnutrition and causes the development of various Geriatric syndromes such as frailty, sarcopenia and falls or negatively affects the course of these diseases $(54,55)$. Dried fruits and vegetables are associated with more positive outcomes in terms of dental health, suggesting that such food should be included in the diet plans for older adults (56). Such effects of dried fruits and vegetables can probably be attributed to the fact that they require more chewing because they are rich in fibre, leading to high production of saliva and they contain substances with antimicrobial properties such as sorbitol $(56,57)$. In a study conducted in Korean adults, vitamin $C$ intake was found to have a negative correlation with periodontitis (58). However, another study conducted in postmenopausal women in Buffalo reported no relationship between vitamin $D$ and periodontal disease (59). Furthermore, another study reported a significant negative correlation among predicted vitamin D levels, tooth loss and periodontitis (60). Antonoglou et al. (61) showed a significant correlation between low doses of vitamin $\mathrm{D}$ and chronic periodontitis. Another systematic review suggests that antioxidant micronutrients that are rich in vitamin $A$ (carotenoids and beta carotene), vitamin C, vitamin $E$, glutathione and melatonin could reduce reactive oxygen species-mediated periodontal tissue inflammation (62).

\section{Snacking Habit}

It is possible to win the battle against chronic diseases and malnutrition, which are commonly encountered in the elderly, because of the properties of dried foods such as their antioxidant effects, high content of micronutrients and fibre and the ability to store and use them in the long term. Snacking is a common eating habit that is observed in up to $85 \%$ older adults. Moreover, daily calorie intake decreases with age and this requires the use of suitable foods for snacking in the elderly (63). For instance, a systematic review showed that the prevention and even reversal of Frailty syndrome are associated with quantitative (energy intake) and qualitative (nutrient quality) factors (64). It is possible to improve the eating habits such as snacking or minimeals by preferring dried fruits and vegetables. In addition, this can be beneficial in reducing the risk and managing metabolic disorders such as Diabetes Mellitus and obesity. A study found that the frequency of daytime eating increased and the mean frequency of daytime eating was six (65). This underlines the advantages of consuming dried fruits and vegetables as daytime snacks in the elderly. Therefore, the addition of such food to the diet plan of older adults in nursing homes and in caregiver trainings would help in developing healthy eating habits. 


\section{Recommended Oral Exercises for the Elderly}

Neurodegenerative diseases, cerebrovascular events and other chronic diseases that occur due to ageing may prevent the maintenance of oral functions such as swallowing, salivation and chewing (66). During this period of life, when we are the most fragile, it is important to prevent or correct the impairment of oral functions to effectively consume foods in sufficient amounts. Simple oral exercises were shown to have positive effects on chewing, salivation and swallowing functions (67). Oral exercise programmes led to improved oral functions and higher quality of life $(68,69)$. Salivation can be increased and the development of functional muscles involved in swallowing can be improved by consuming foods that are rich in fibre such as dried fruits and vegetables as well as by chewing them more. This can possibly contribute to regain the lost functions and to reduce the risk of malnutrition, similar to the simple oral exercises in older patients. Using dried fruits and vegetables is suggested to improve oral functions such as swallowing and chewing that can partly increase the chances of surviving life-threatening conditions such as pulmonary aspiration and malnutrition in the elderly, similar to the exercise programmes mentioned in previous studies.

\section{Economic Vulnerability in the Elderly}

Consuming fruits and vegetables that can be bought at reasonable prices in their respective season and then dried, particularly in the winter, can be recommended as an alternative solution to the economic vulnerability among the elderly. Many older adults have financial problems when they retire, which negatively affects their eating habits $(70,71)$. Fresh fruits and vegetables or most of the foods that we consume daily are wasted because we cannot store them for long. The wastage of dried fruits and vegetables is lower than that of fresh fruits and vegetables because they can be stored and have a longer shelf life. In addition to the sharp increase in the off-season food prices, the fact that these products cannot be dried because of local individual's unawareness or lack of effective organisations causes considerable labour and financial losses in tropical countries such as India. Graphic I shows that the proportion of dried food consumption (72).

\section{Physical Limitations of the Elderly}

Older adults have an increased need for foods that do not spoil and can be stored for a long time, especially when they have to live alone. Dried foods and vegetables that can be stored at home for long become more important because of the psychological and physical limitations of older adults such as their inability to do gardening or to frequently visit a store or shopping mall $(73,74)$. Making 'finger foods', which can be consumed by older adults who cannot hold a fork and spoon, available to the elderly at all times may partially prevent the development

\section{U.S. per capita loss-adjusted fruit availability, 2017}

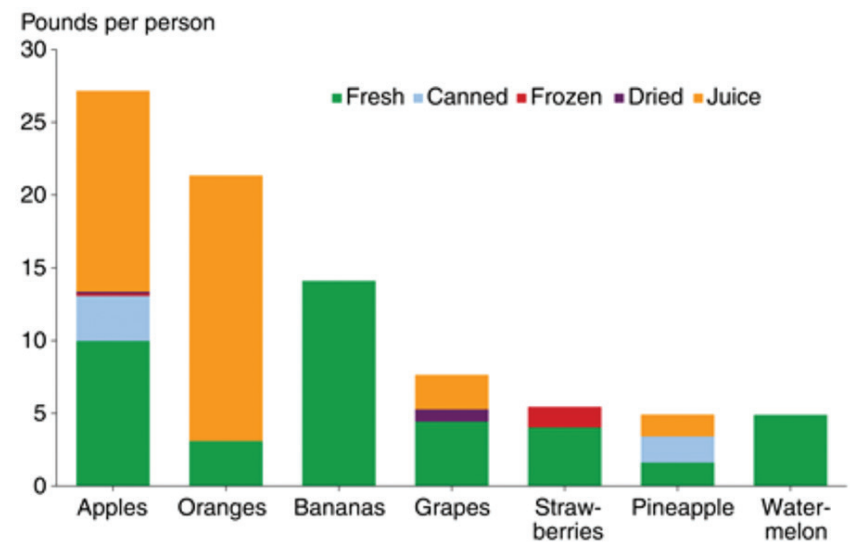

Loss-adjusted food availability data are proxies for consumption. Source: USDA, Economic Research Service, Loss-Adjusted Food Availability Data.

Graphic I. Unites States per capita loss-adjusted fruit availability, United States Department of Agriculture Economic Research Service, 2017. This shows that awareness studies should be conducted to increase the consumption of dried foods

of malnutrition. The 2019 ESPEN guidelines underline the importance of the consumption of finger foods by older adults who cannot hold a fork and spoon $(75,76)$. Thus, dried foods can be suggested as an alternative to prevent malnutrition and increase the tendency to eat as well as to ensure adherence to the diet in the elderly.

\section{Effects on the Microbiota}

Diet plays a key role in shaping the microbiome and a negatively affected intestinal microbiome is associated with chronic diseases such as cancer, inflammatory bowel disease, cardiovascular diseases, type 2 Diabetes Mellitus and obesity (77). Phytochemicals and fibres present in dried fruits affect the composition and activity of the intestinal microbiota (78). The bioactive components of dried fruits, i.e. polyphenols, are prebiotics and they render non-pathogenic microbiota dominant (79). In a study comparing diets that are rich in fruits and vegetables such as the Mediterranean diet and the modern lowfibre diets that are rich in fats and high in calories, it was found that the microbiome-related metabolomic profile improved in the group that received the Mediterranean diet (80).

\section{Cardiovascular Benefits}

The third most common risk factor for non-communicable diseases after hypertension and smoking is the low consumption of fruits and vegetables. The consumption of low fruits causes a higher risk of non-communicable diseases than the consumption of other foods such as vegetables, whole wheat products, fish, legumes etc (81). Cardiovascular disease is a global health problem and various studies have shown the importance of fresh as well as dried fruits and vegetables in protection against cardiovascular diseases $(82,83)$. The positive effects of these food on the 
cardiovascular system are thought to stem from their effects concerning the protection of the vascular endothelial function, regulation of the lipid metabolism and blood pressure, inhibition of platelet functions, reduction in ischaemic reperfusion injury, suppression of thrombosis and reduction in oxidative stress and inflammation (84). Phytonutrients comprising polyphenols have many health benefits because they have antioxidative effects, lead to vasodilatation and prevent postprandial glucose peaks etc (85). The cardiometabolic effects of phytonutrients (tocopherols, carotenoids, polyphenols and phenolic acids) are improved due to their antioxidant properties, because they reduce blood pressure via vasodilatation (polyphenols cause relaxation of venous smooth muscles) and have low sodium and high potassium contents (86). In a prospective study conducted in 34.489 postmenopausal women, it was shown that foods rich in flavonoids reduced the incidence of cardiovascular disease and all causes of cardiovascular deaths (87).

\section{Improvement in Cognitive Functions}

Age-related decline in cognitive functions and the risk of neurodegenerative diseases can be reduced by the intake of antioxidant and anti-inflammatory components present in high amounts in fruits and vegetables (88). According to a prospective study that investigated flavonoids and decline in cognitive functions in 1.640 geriatric subjects who were not diagnosed with dementia, high intake of flavonoids led to a better cognitive performance (89). A diet that is rich in flavonoids results in improved cognitive functions, delayed onset of Alzheimer's and decreased incidence of Parkinson's disease. The positive effects of flavonoids on memory and neurocognitive performance are believed to stem from their protective effect on fragile neurons as well as their improving effect on the existing neuronal functions and neuronal regeneration (90). The Kame Project cohort study underlined that the oxidative damage caused by beta-amyloid peptides in Alzheimer's disease could be partly reduced by the consumption of fruits and vegetables (91). Endogenous neurotoxins play a role in the aetiology of Parkinson's disease and polyphenols reduce neuronal damage in such patients (92). This study and other similar studies question the role of consuming dried fruits and vegetables due to the fact that there is no potent and effective treatment option for neurodegenerative diseases such as dementia, Alzheimer's and Parkinson's, which are public health problems; the longterm use of dried fruits and vegetables during the pre-geriatric period might potentially reduce the workload of the society and healthcare facilities and have a positive effect on the onset and course of chronic diseases.

\section{Increased Acid Load in the Elderly}

Buffer systems such as the kidneys and lungs that provide the acid-base balance become insufficient due to age-related decline in physiological functions and reserves as well as the increased incidence of chronic pathologies during the ageing process $(93,94)$. The preservation of lean body mass is of great importance in terms of the development of chronic diseases and related comorbidities in the geriatric population (95). An alkaline diet preserves lean body mass (96). Our ancestors predominantly adopted vegan eating habits; therefore their systemic $\mathrm{pH}$ was rather alkaline. However, we now consume high amounts of animal proteins, which negatively affect the acid load that has already increased in the elderly (97). Micronutrient deficiencies that increase with ageing become more severe due to the increased acid load and homeostatic mechanisms also start to fail, e.g. urinary excretion of calcium increases, bone mineral density decreases, urolithiasis develops and renal failure becomes more severe $(98,99)$. Thus, the acid load in the elderly may further increase in modern times, which can be explained by comparing the current dietary fibre consumption with that in the old times. Our ancestors used to daily consume $>100 \mathrm{mg}$ of dietary fibre, whereas in the modern age, the daily intake of dietary fibre has dropped to $10 \mathrm{mg}$, showing how dietary factors have changed over the years and exceeded the limits of adaptational change (100). It is possible to decrease the acid-base imbalance to some extent by adding dried fruits and vegetables to the dietary treatment plans prepared for the elderly.

\section{Conclusion and Recommendations}

With the elderly population increasing in number and proportion and healthcare systems on the verge of collapse, it would be wise to realise the importance of dried fruits and increase the awareness of disease prevention with the factors that could reduce the severity of diseases in the elderly. The course of chronic metabolic diseases and the ageing process can be improved by increasing dried fruit and vegetable consumption among the elderly. Literature data that include a multifaceted analyses and recommendations concerning the consumption of dried fruits and vegetables in the elderly are limited. Therefore, extensive and long-term studies on the use of dried foods in the elderly are needed.

\section{Ethics}

Peer-review: Internally peer-review.

\section{Author Contributions}

Concept: T.B., Design: T.B., Data Collection or Processing: T.B., A.Y., S.F.A., Analysis or Interpretation: T.B., A.Y., S.F.A., Literature Search: T.B., A.Y., S.F.A., Writing: T.B.

Conflict of Interest: The authors have no conflicts of interest to report.

Financial Disclosure: The authors declared that this study received no financial support. 


\section{References}

1. Cereda E, Pedrolli C, Klersy C, Bonardi C, Quarleri L, Cappello S, Turri A, Rondanelli M, Caccialanza R. Nutritional status in older persons according to healthcare setting: A systematic review and meta-analysis of prevalence data using MNA $^{\circledR}$. Clin Nutr 2016;35:1282-1290.

2. Schneider SM, Al-Jaouni R, Pivot $X$, Braulio VB, Rampal $P$, Hebuterne $X$. Lack of adaptation to severe malnutrition in elderly patients. Clin Nutr 2002;21:499-504.

3. Volkert D, Beck AM, Cederholm T, Cereda E, Cruz-Jentoft A, Goisser $\mathrm{S}$, de Groot L, Großhauser F, Kiesswetter E, Norman K, Pourhassan M, Reinders I, Roberts HC, Rolland Y, Schneider SM, Sieber CC, Thiem U, Visser M, Wijnhoven HAH, Wirth R. Management of Malnutrition in Older PatientsCurrent Approaches, Evidence and Open Questions. J Clin Med 2019;8:974.

4. Evans $\mathrm{C}$. Malnutrition in the elderly: a multifactorial failure to thrive. Perm J 2005;9:38-41.

5. Mack L. 2001. Food Preservation in the Roman Empire. Chapel Hill, NC. University of North Carolina. Available from: http://www.unc.edu/courses/ rometech/public/content/survival/Lindsay_Mack/Food_Preservation.htm.

6. Wilson AC. 1991. Preserving Food to Preserve Life: The Response to Glut and Famine from Early Times to the End of the Middle Ages in "Waste Not, Want Not": Food Preservation from Early Times to the Present, Available from: https://www.questia.com/library/103265138/waste-not-want-not-foodpreservation-from-early

7. Nummer BA. Historical Origins of Food Preservation National Center for Home Food Preservation May 2002 Available from: https://nchfp.uga.edu/ publications/nchfp/factsheets/food_pres_hist.html

8. 8. Valigra L. The Father of Food Preservation. 2011. Available from: https:// www.foodqualityandsafety.com/article/the-father-of-food-preservation/

9. Sormaz U, Onur N., Güneş E, Nızamlıoglu F, Regional Differences in Traditional Products of Turkish Cuisine: The Example of Tarhana, Aydın Gastronomy Journal Available from : https://dergipark.org.tr/tr/download/ article-file/637409

10. United States War Department (1919), Annual Report of the Secretary of War, Available from: https://books.google.com.tr/ books?id=Tbw0AQAAMAAJctdq=inauthor\%3A\%22United\%20States.\%20 War\%20Department\%22\&thl=tr\&tpg $=P P 14 \# v=$ onepagectq\&f =false

11. Shifler Bowers K, Francis E, Kraschnewski JL. The dual burden of malnutrition in the United States and the role of non-profit organizations. Prev Med Rep 2018;12:294-297.

12. Kendall P, Sofos J. Drying Fruits, Food and Nutrition Series, No. 9.309. Fort Collins, C0: Colorado State University Extension. Available from: https:/ extension.colostate.edu/topic-areas/nutrition-food-safety-health/dryingvegetables-9-308/

13. Historical Origins of Food Preservation Brian A. Nummer. National Center for Home Food Preservation 2002. Available from: https://nchfp.uga.edu/ publications/nchfp/factsheets/food_pres_hist.html

14. Jay JM, Loessner M, Golden DA. Protection of Foods by Drying. In: Modern Food Microbiology. Food Science Text Series. Springer, 2005, pp 443-456.

15. Chitrakar B, Zhang $M$, Adhikari B. Dehydrated foods: Are they microbiologically safe? Crit Rev Food Sci Nutr 2018;59:2734-2745.

16. Pittia, P, Antonello P. Safety by Control of Water Activity: Drying, Smoking, and Salt or Sugar Addition. Elsevier Inc 2016:7-28.

17. Montgomery SC, Streit SM, Beebe ML, Maxwell PJ 4th. Micronutrient Needs of the Elderly. Nutr Clin Pract 2014;29:435-444.

18. Conzade R, Koenig W, Heier M, Schneider A, Grill E, Peters A, Thorand B. Prevalence and Predictors of Subclinical Micronutrient Deficiency in German Older Adults: Results from the Population-Based KORA-Age Study. Nutrients 2017;9:1276.

19. Patel D, Kalkat P, Baisch D, Zipser R. Celiac disease in the elderly. Gerontology 2005:51:213-214
20. Heidelbaugh JJ. Proton pump inhibitors and risk of vitamin and mineral deficiency: evidence and clinical implications. Ther Adv Drug Saf 2013:4:125-133.

21. Nagpal R, Mainali $R$, Ahmadi $S$, Wang $S$, Singh $R$, Kavanagh $K$, Kitzman DW, Kushugulova A, Marotta F, Yadav H. Gut microbiome and aging: Physiological and mechanistic insights. Nutr Healthy Aging 2018;4:267285.

22. Aziz $F$, Patil P. Role of prophylactic vitamin $\mathrm{K}$ in preventing antibiotic induced hypoprothrombinemia. Indian J Pediatr 2015;82:363-367.

23. Odamaki T, Kato K, Sugahara H, Hashikura N, Takahashi S, Xiao J, Osawa R. Age-related changes in gut microbiota composition from newborn to centenarian: a cross-sectional study. BMC Microbiology 2016;16.

24. Rinninella E, Mele MC, Merendino N, Cintoni M, Anselmi G, Caporossi A Gasbarrini A, Minnella AM. The Role of Diet, Micronutrients and the Gut Microbiota in Age-Related Macular Degeneration: New Perspectives from the Gut-Retina Axis. Nutrients 2018;10:1677.

25. Biesalski H. Nutrition meets the microbiome: micronutrients and the microbiota. Ann N Y Acad Sci 2016;1372:53-64.

26. Shea-Donohue T, Qin B, Smith A. Parasites, nutrition, immune responses and biology of metabolic tissues. Parasite Immunol 2017;39.

27. Hesham MS, Edariah $A B$, Norhayati M. Intestinal parasitic infections and micronutrient deficiency: a review. Med J Malaysia 2004;59:284-293.

28. Feng B, Zhu X, Zhou B, Su D, Huang L, Huang E, Zhao D, Zhang R. [Dietary microelements intakes status of elderly people from different areas in Zhejiang Province in 2010-2012]. Wei Sheng Yan Jiu 2019;48:728-732.

29. Hoffman R. Micronutrient deficiencies in the elderly - could ready meals be part of the solution? J Nutr Sci 2017;6:e2.

30. Higgs J, Derbyshire E, Styles K. Nutrition and osteoporosis prevention for the orthopaedic surgeon: A wholefoods approach. EFORT Open Rev 2017;2:300-308.

31. Kamiloglu S, Toydemir G, Boyacioglu D, Beekwilder J, Hall RD, Capanoglu E. A Review on the Effect of Drying on Antioxidant Potential of Fruits and Vegetables. Crit Rev Food Sci Nutr 2016;56(Suppl 1):110-129.

32. Ntagkas N, Woltering E, Bouras $\mathrm{S}$, de Vos RC, Dieleman JA, Nicole CC, Labrie C, Marcelis LF. Light-Induced Vitamin C Accumulation in Tomato Fruits is Independent of Carbohydrate Availability. Plants (Basel) 2019;8:86.

33. Storey $M$, Anderson P. Total fruit and vegetable consumption increases among consumers of frozen fruit and vegetables. Nutrition 2018;46:115-121.

34. Dreher ML. Whole fruits and fruit fiber emerging health effects. Nutrients 2018;10:1833.

35. Gupta S, Gowri BS, Lakshmi AJ, Prakash J. Retention of nutrients in green leafy vegetables on dehydration. J Food Sci Technol 2013;50:918-925.

36. US Department of Agriculture 2010, Agricultural Research Service. What We Eat in America: Nutrient intakes from food by gender and age. National Health and Nutrition Examination Survey (NHANES) 2009-10. Available from: http://www.ars.usda.gov/Sp2userfiles/Place/12355000/Pdf/0910/ Table_1_Nin_Gen_09.Pdf.

37. Institute of Medicine 2005, Food and Nutrition Board. Dietary Reference Intakes: Energy, Carbohydrates, Fiber, Fat, Fatty Acids, Cholesterol, Protein and Amino Acids. Washington, DC: National Academies Press; 2005.

38. Post RE, Mainous AG 3rd, King DE, Simpson KN. Dietary fiber for the treatment of type 2 Diabetes Mellitus: a meta-analysis. J Am Board Fam Med 2012;25:16-23.

39. Kim Y, Je Y. Dietary fibre intake and mortality from cardiovascular disease and all cancers: A meta-analysis of prospective cohort studies. Arch Cardiovasc Dis 2016;109:39-54.

40. Staller $K_{1}$ Song $M$, Grodstein $F_{1}$ Whitehead WE, Matthews CA, Kuo B, Chan AT. Increased Long-term Dietary Fiber Intake Is Associated With a Decreased Risk of Fecal Incontinence in Older Women. Gastroenterology 2018:155:661-667. 
41. Kaluza J, Harris $H$, Wallin $A$, Linden $A$, Wolk A. Dietary Fiber Intake and Risk of Chronic Obstructive Pulmonary Disease: A Prospective Cohort Study of Men. Epidemiology 2018;29:254-260

42. Song $Y$, Liu $M$, Yang FG, Cui LH, Lu XY, Chen C. Dietary fibre and the risk of colorectal cancer: a case- control study. Asian Pac J Cancer Prev 2015; 16:3747-3752.

43. Zheng $B$, Shen $H$, Han $H_{1}$ Han T, Qin Y. Dietary fiber intake and reduced risk of ovarian cancer: a meta-analysis. Nutr J 2018;17:99.

44. Sun $L, Z$ hang $Z, X u J, X u$ G, Liu X. Dietary fiber intake reduces risk for Barrett's esophagus and esophageal cancer. Crit Rev Food Sci Nutr 2017;57:27492757.

45. Harnden KK, Blackwell KL. Increased fiber intake decreases premenopausal breast cancer risk. Pediatrics 2016;137:e20154376.

46. Milisav I. Antioxidants as dietary supplements for the elderly. Clin Nutr ESPEN 2016;14:50-51.

47. Conti V, Izzo V, Corbi G, Russomanno G, Manzo V, De Lise F, Di Donato A, Filippelli A. Antioxidant supplementation in the treatment of agingassociated diseases. Front Pharmacol 2016;7:24.

48. Liguori I, Russo G, Curcio F, Bulli G, Aran L, Della-Morte D, Gargiulo G, Testa G, Cacciatore F, Bonaduce D, Abete P. Oxidative stress, aging, and diseases. Clin Interv Aging 2018;13:757-772.

49. Mayne ST. Antioxidant nutrients and chronic disease: use of biomarkers of exposure and oxidative stress status in epidemiologic research. J Nutr 2003;133(Suppl 3):933S-940S.

50. Kaliora AC, Dedoussis GV, Schmidt H. Dietary antioxidants in preventing atherogenesis. Atherosclerosis 2006;187:1-17.

51. Pham DQ, Plakogiannis R. Vitamin E supplementation in cardiovascular disease and cancer prevention: Part 1. Ann Pharmacother 2005;39:18701878.

52. Marshall TA, Warren JJ, Hand JS, Xie XJ, Stumbo PJ. Oral health, nutrient intake and dietary quality in the very old. J Am Dent Assoc 2002;133:13691379.

53. Sheiham A, Steele J. Does the condition of the mouth and teeth affect the ability to eat certain foods, nutrient and dietary intake and nutritional status amongst older people? Public Health Nutr 2001;4:797-803.

54. Avlund K, Holm-Pedersen $\mathrm{P}$, Morse DE, Viitanen M, Winblad B. Tooth loss and caries prevalence in very old Swedish people: The relationship to cognitive function and functional ability. Gerodontology 2004;21:17-26.

55. Samnieng P, Ueno M, Shinada K, Zaitsu T, Wright FAC, Kawaguchi Y. Oral health status and chewing ability is related to Mini-Nutritional Assessment results in an older adult population in Thailand. J Nutr Gerontol Geriatr 2011;30:291-304.

56. Sadler MJ. Dried fruit and dental health. Int J Food Sci Nutr 2016;67:944959.

57. Smolarek PC, Esmerino LA, Chibinski AC, Bortoluzzi MC, dos Santos EB, Junior VAK. In vitro antimicrobial evaluation of toothpastes with natural compounds. Eur J Dent 2015;9:580-586.

58. Lee JH, Shin MS, Kim EJ, Ahn YB, Kim HD. The association of dietary vitamin C intake with periodontitis among Korean adults: Results from KNHANES IV. PLoS One 2017;12:e0177074.

59. Pavlesen S, Mai X, Wactawski-Wende J, LaMonte MJ, Hovey KM, Genco RJ, Millen AE. Vitamin D status and tooth loss in postmenopausal females: The Buffalo Osteoporosis and Periodontal Disease (OsteoPerio) Study. J Periodontol 2016;87:852-863.

60. Jimenez M, Giovannucci E, Krall Kaye E, Joshipura KJ, Dietrich T. Predicted vitamin $D$ status and incidence of tooth loss and periodontitis. Public Health Nutr 2014;17:844-852.

61. Antonoglou $G$, Knuuttila $M$, Niemelä $O$, Raunio $T$, Karttunen $R$, Vainio 0, Hedberg P, Ylöstalo P, Tervonen T. Low serum level of 1,25(OH)2D is associated with chronic periodontitis. J Periodont Res 2015;50:274-280.
62. Muniz FW, Nogueira SB, Mendes FL, Rösing CK, Moreira MM, de Andrade GM, Carvalho Rde S. The impact of antioxidant agents complimentary to periodontal therapy on oxidative stress and periodontal outcomes: A systematic review. Arch Oral Biol 2015;60:1203-1214.

63. Zizza CA, Tayie FA, Lino M. Benefits of snacking in older Americans. J Am Diet Assoc 2007;107:800-806.

64. Lorenzo-López L, Maseda A, de Labra C, Regueiro-Folgueira L, RodríguezVillamil JL, Millán-Calenti JC. Nutritional determinants of frailty in older adults: A systematic review. BMC Geriatr 2017;17:108.

65. Gill S, Panda S. 2015. A smartphone app reveals erratic diurnal eating patterns in humans that can be modulated for health benefits. Cell Metab 2015;22:789-798.

66. Kang JH, Park RY, Lee SJ, Kim JY, Yoon SR, Jung KI. The effect of bedside exercise program on stroke patients with dysphagia. Ann Rehabil Med 2012;36:512-520.

67. Kim HJ, Lee JY, Lee ES, Jung HJ, Ahn HJ, Kim BI. Improvements in oral functions of elderly after simple oral exercise. Clin Interv Aging 2019;14:915-924.

68. Ibayashi H, Fujino Y, Pham TM, Matsuda S. Intervention study of exercise program for oral function in healthy elderly people. Tohoku J Exp Med 2008;215:237-245.

69. Hakuta C, Mori C, Ueno M, Shinada K, Kawaguchi Y. Evaluation of an oral function promotion programme for the independent elderly in Japan. Gerodontology 2009;26:250-258.

70. Griep MI, Mets TF, Collys K, Ponjaert-Kristoffersen I, Massart DL. Risk of malnutrition in retirement homes elderly persons measured by the "mininutritional assessment". J Gerontol A Biol Sci Med Sci 2000;55:M57-63.

71. Donini LM, Scardella P, Piombo L, Neri B, Asprino R, Proietti AR, Carcaterra S, Cava E, Cataldi S, Cucinotta D, Di Bella G, Barbagallo M, Morrone A. Malnutrition in elderly: social and economic determinants. J Nutr Health Aging 2013;17:9-15.

72. United States Department of Agriculture Economic Research Service, 2017, U.S per capita loss-adjusted fruit availability, Available from: https://www.ers.usda.gov/data-products/chart-gallery/gallery/chartdetail/?chartld $=58322$

73. Martins JA, Merighi MAB, Jesus MCP, Watanabe HAW. Aging with physical disabilities: experience intersected by stigma, social isolation and finitude. Escola Anna Nery 2018;22:e20180128.

74. Shrivastava SR, Shrivastava PS, Ramasamy J. Health-care of Elderly: Determinants, Needs and Services. Int J Prev Med 2013;4:1224-1225.

75. Evans $\mathrm{C}$. Malnutrition in the elderly: a multifactorial failure to thrive. Perm J 2005;9:38-41.

76. Volkert D, Beck AM, Cederholm T, Cruz-Jentoft A, Goisser S, Hooper L, Kiesswetter E, Maggio M, Raynaud-Simon A, Sieber CC, Sobotka L, van Asselt D,Wirth R, Bischoff SC. ESPEN guideline on clinical nutrition and hydration in geriatrics. Clin Nutr 2019;38:10-47.

77. Singh RK, Chang HW, Yan D, Lee KM, Ucmak D, Wong K, Abrouk M, Farahnik B, Nakamura M, Zhu TH, Bhutani T, Liao W. Influence of diet on the gut microbiome and implications for human health. J Transl Med 2017;15:73.

78. Wijayabahu AT, Waugh SG, Ukhanova M, Mai V. Dietary raisin intake has limited effect on gut microbiota composition in adult volunteers. Nutrition Journal 2019;18:14.

79. Cardona F, Andrés-Lacueva C, Tulipani S, Tinahones FJ, Queipo-Ortuño $\mathrm{MI}$. Benefits of polyphenols on gut microbiota and implications in human health. J Nutr Biochem 2013;24:1415-1422.

80. De Filippis F, Pellegrini N, Vannini L, Jeffery IB, La Storia A, Laghi L, Serrazanetti DI, Di Cagno R, Ferrocino I, Lazzi C, Turroni S, Cocolin L, Brigidi P, Neviani E, Gobbetti M, O'Toole PW, Ercolini D. High-level adherence to a Mediterranean diet beneficially impacts the gut microbiota and associated metabolome. Gut 2016;65:1812-1821. 
81. Ezzati M, Riboli E. Behavioral and dietary risk factors for noncommunicable diseases. N Engl J Med 2013;369:954-964.

82. Alissa EM, Ferns GA. Dietary fruits and vegetables and cardiovascular diseases risk. Crit Rev Food Sci Nutr 2017;57:1950-1962.

83. Carughi A, Feeney MJ, Kris-Etherton P, Fulgoni V 3rd, Kendall CW, Bulló $M$, Webb D. Pairing nuts and dried fruit for cardiometabolic health. Nutr J 2016;15:23.

84. Zhao CN, Meng X, Li Y, Li S, Liu Q, Tang GY, Li HB. Fruits for Prevention and Treatment of Cardiovascular Diseases. Nutrients 2017;9:598.

85. Adamska-Patruno E, Billing-Marczak K, Orlowski M, Gorska M, Krotkiewski M, Kretowski A. A Synergistic Formulation of Plant Extracts Decreases Postprandial Glucose and Insulin Peaks: Results from Two Randomized, Controlled, Cross-Over Studies Using Real-World Meals. Nutrients 2018;10:956.

86. Vasanthi HR, ShriShriMal N, Das DK. Phytochemicals from plants to combat cardiovascular disease. Curr Med Chem 2012;19:2242-2251.

87. Mink PJ, Scrafford CG, Barraj LM, Harnack L, Hong CP, Nettleton JA, Jacobs DR Jr. Flavonoid intake and cardiovascular disease mortality: a prospective study in postmenopausal women. Am J Clin Nutr 2007;85:895-909.

88. Joseph J, Cole G, Head E, Ingram D. Nutrition, brain aging, and neurodegeneration. J Neurosci 2009;29:12795-12801.

89. Letenneur L, Proust-Lima C, Le Gouge A, Dartigues JF, Barberger-Gateau P. Flavonoid intake and cognitive decline over a 10-year period. Am J Epidemiol 2007;165:1364-1371.

90. Spencer JP. Food for thought: the role of dietary flavonoids in enhancing human memory, learning and neuro-cognitive performance. Proc Nutr Soc $2008 ; 67: 238-252$
91. Dai Q, Borenstein AR, Wu Y, Jackson JC, Larson EB. Fruit and vegetable juices and Alzheimer's disease: the Kame Project. Am J Med 2006;119:751-759.

92. Vauzour D, Ravaioli G, Vafeiadou K, Rodriguez-Mateos A, Angeloni $C$, Spencer JP. Peroxynitrite induced formation of the neurotoxins 5-S-cysteinyl-dopamine and DHBT-1: implications for Parkinson's disease and protection by polyphenols. Arch Biochem Biophys 2008;476:145-151.

93. Nabata T, Morimoto $S$, Ogihara T. [Abnormalities in acid-base balance in the elderly]. Nihon Rinsho 1992;50:2249-2253.

94. Bergman A, Atzmon G, Ye K, MacCarthy T, Barzilai N. Buffering mechanisms in aging: a systems approach toward uncovering the genetic component of aging. PLoS Comput Biol 2007;3:e170.

95. Boutari C, Mantzoros CS. Decreasing lean body mass with age: challenges and opportunities for novel therapies. Endocrinol Metab (Seoul) 2017;32:422-425.

96. Dawson-Hughes B, Harris SS, Ceglia L. Alkaline diets favor lean tissue mass in older adults. Am J Clin Nutr 2008:8:662-665.

97. Sebastian A, Frassetto LA, Sellmeyer DE, Merriam RL, Morris RC Jr. Estimation of the net acid load of the diet of ancestral preagricultural Homo sapiens and their hominid ancestors. Am J Clin Nutr 2002;76:1308-1316.

98. Frassetto L, Morris RC Jr, Sellmeyer DE, Todd K, Sebastian A. Diet, evolution and aging--the pathophysiologic effects of the post-agricultural inversion of the potassium-to-sodium and base-to-chloride ratios in the human diet. Eur J Nutr 2001;40:200-213.

99. Berardi JM, Logan AC, Rao AV. Plant based dietary supplement increases urinary pH. J Int Soc Sports Nutr 2008;5:20.

100. Eaton SB. The ancestral human diet: what was it and should it be a paradigm for contemporary nutrition? Proc Nutr Soc 2006;65:1-6. 